\title{
Clustering of Hypoglycemia Events in Patients With Hyperinsulinism: Extension of the Digital Phenotype Through Retrospective Data Analysis
}

Chris Worth ${ }^{1,2}$, BMedSci, MBChB; Simon Harper ${ }^{2}$, MEng (Hons), PhD; Maria Salomon-Estebanez ${ }^{1}$, MBBS, MPhil; Elaine O'Shea ${ }^{1}$, Bsc (Hons); Paul W Nutter ${ }^{2}$, BEng (Hons), MSc, PhD; Mark J Dunne ${ }^{3}$, BSc, PhD; Indraneel Banerjee ${ }^{1,3}$, MBBS, MD

\footnotetext{
${ }^{1}$ Department of Paediatric Endocrinology, Royal Manchester Children's Hospital, Manchester, United Kingdom

${ }^{2}$ Department of Computer Science, University of Manchester, Manchester, United Kingdom

${ }^{3}$ Faculty of Biology, Medicine and Health, University of Manchester, Manchester, United Kingdom
}

\section{Corresponding Author:}

Chris Worth, BMedSci, MBChB

Department of Paediatric Endocrinology

Royal Manchester Children's Hospital

Oxford Road

Manchester, M13 9WL

United Kingdom

Phone: 4407837740913

Email: christophersimon.worth@mft.nhs.uk

\section{Abstract}

Background: Hyperinsulinism (HI) due to excess and dysregulated insulin secretion is the most common cause of severe and recurrent hypoglycemia in childhood. High cerebral glucose use in the early hours results in a high risk of hypoglycemia in people with diabetes and carries a significant risk of brain injury. Prevention of hypoglycemia is the cornerstone of the management of $\mathrm{HI}$, but the risk of hypoglycemia at night or the timing of hypoglycemia in children with $\mathrm{HI}$ has not been studied; thus, the digital phenotype remains incomplete and management suboptimal.

Objective: This study aims to quantify the timing of hypoglycemia in patients with $\mathrm{HI}$ to describe glycemic variability and to extend the digital phenotype. This will facilitate future work using computational modeling to enable behavior change and reduce exposure of patients with $\mathrm{HI}$ to injurious hypoglycemic events.

Methods: Patients underwent continuous glucose monitoring (CGM) with a Dexcom G4 or G6 CGM device as part of their clinical assessment for either $\mathrm{HI}(\mathrm{N}=23)$ or idiopathic ketotic hypoglycemia (IKH; N=24). The CGM data were analyzed for temporal trends. Hypoglycemia was defined as glucose levels $<3.5 \mathrm{mmol} / \mathrm{L}$.

Results: A total of 449 hypoglycemic events totaling 15,610 minutes were captured over 237 days from 47 patients (29 males; mean age 70 months, SD 53). The mean length of hypoglycemic events was 35 minutes. There was a clear tendency for hypoglycemia in the early hours (3-7 AM), particularly for patients with HI older than 10 months who experienced hypoglycemia $7.6 \%$ (1480/19,370 minutes) of time in this period compared with 2.6\% (2405/92,840 minutes) of time outside this period $(P<.001)$. This tendency was less pronounced in patients with $\mathrm{HI}$ who were younger than 10 months, patients with a negative genetic test result, and patients with IKH. Despite real-time CGM, there were 42 hypoglycemic events from 13 separate patients with HI lasting >30 minutes.

Conclusions: This is the first study to have taken the first step in extending the digital phenotype of $\mathrm{HI}$ by describing the glycemic trends and identifying the timing of hypoglycemia measured by CGM. We have identified the early hours as a time of high hypoglycemia risk for patients with HI and demonstrated that simple provision of CGM data to patients is not sufficient to eliminate hypoglycemia. Future work in HI should concentrate on the early hours as a period of high risk for hypoglycemia and must target personalized hypoglycemia predictions. Focus must move to the human-computer interaction as an aspect of the digital phenotype that is susceptible to change rather than simple mathematical modeling to produce small improvements in hypoglycemia prediction accuracy. 
(J Med Internet Res 2021;23(10):e26957) doi: 10.2196/26957

\section{KEYWORDS}

hyperinsulinism; continuous glucose monitoring; digital phenotype; hypoglycemia; nocturnal hypoglycemia

\section{Introduction}

\section{Background}

Hyperinsulinism (HI) is a diverse collection of disorders united by the pathology of inappropriate insulin secretion causing hyperinsulinemic hypoglycemia with simultaneous suppression of alternative fuel sources. It has an estimated incidence of $1: 28,000$ in the United Kingdom [1] and is the most common cause of severe and recurrent hypoglycemia in childhood. This recurrent hypoglycemia, with the corresponding suppression of ketones as an alternative fuel source, results in brain damage in an unacceptably high proportion of cases, up to $48 \%$ [2]. The risk of brain damage is independent of the chronicity of the disease [3], as damage often occurs early in life when the neonatal brain is highly susceptible to such insults $[4,5]$.

Significant progress in the understanding of the underlying pathophysiology of HI has been made since its first detailed description in 1953 [6]. Increased knowledge of changes at the organic [7], cellular [8], and genetic [9,10] levels has led to improvements in the care of these patients, and recent studies even suggest a lowering of the subsequent rate of brain injury [11]. As first suggested by Richard Dawkins in 1976, there is an "extended phenotype" of all conditions, not just limited to observable physical traits or cellular changes [12]. The most recent extension of this is that of a digital phenotype, encompassing aspects of patients' behaviors related to and measured by technology [13]. The digital phenotype includes everything from interactions with others on social media to digitally collected location data and continuously measured physiological parameters, such as glucose levels and heart rate. These measures sit alongside the traditional characterization of diseases to form a more comprehensive picture and facilitate a more nuanced approach to management. Current management of $\mathrm{HI}$ is complex, balancing the risks and benefits of a limited repertoire of medications, all of which have a small therapeutic window and significant side effect profiles [14]. Because of the dysregulated secretion of insulin in these patients, hypoglycemic events are often very difficult to predict. The standard of care for home monitoring of hypoglycemia is intermittent fingerpick testing for blood glucose. However, patients rarely achieve more than three to four such measurements per day and this infrequent testing strategy risks missing hypoglycemia between tests, particularly overnight [15]. This practice also offers little in the way of disease characterization and does very little to extend the phenotype or the scientific understanding of HI.

In recent years, continuous glucose monitoring (CGM) has emerged as an alternative, offering insight into glucose trends. CGM measures subcutaneous glucose at frequent intervals over extended periods (7-10 days) to provide glycemic phenotypes in patients with hypoglycemia and diabetes and contributes to the digital phenotype [16]. The application of CGM may not yet be readily applicable in patients with $\mathrm{HI}$ as a reliable means of hypoglycemia detection or prediction [17]. However, as CGM is a passive form of monitoring, it can record data at a high granularity with very minimal response burden on users [18]; therefore, it has the potential to collect detailed glycemic data while being acceptable to patients on a long-term basis. There have been a limited number of studies describing the utility of CGM in patients with HI [19-22], and none have described the timing of hypoglycemia events or glycemic trends.

There is good empirical evidence [23] to suggest that hypoglycemic events may not be evenly distributed throughout the day and that the risk of hypoglycemia may be disproportionately higher during periods of reduced food intake. In all but the youngest children, each day is divided into two distinct phases, one of activity and eating and the other of fasting and rest [23]. It is well established that hormones such as cortisol vary throughout the day, with peak levels varying in relation to the time of sunrise [24]. Glucose homeostasis also varies with the time of day [25], but this variability is not likely to be directly related to cortisol [26,27]. Rather, there is likely a direct circadian control involving the suprachiasmatic nucleus in the hypothalamus [28,29] and peripheral clock-gene-regulated components in the pancreas [23].

Before waking, early morning is a high-risk period for hypoglycemia, as glucose use is at its highest [23]. Normally, this is counteracted by a high rate of gluconeogenesis [23]; however, in patients with $\mathrm{HI}$, this is suppressed owing to inappropriate secretion of insulin, resulting in an imbalance of glucose homeostasis weighted toward hypoglycemia [30]. The high risk in early morning is exacerbated by the time-independent, high-glucose requirement of the brain during late sleep [31].

Despite over 30 years of investigation into nocturnal hypoglycemia in children with diabetes [32], the estimated incidence remains as high as $68 \%$ [33]. More than half of all severe hypoglycemic events occur overnight [34], and up to $18 \%$ of deaths in younger patients with diabetes are attributed to nocturnal hypoglycemia [35].

The potential for CGM data to contribute to the digital phenotype of HI has not yet been investigated. Despite the physiological and empirical evidence from healthy participants and participants with diabetes regarding the risks of nocturnal hypoglycemia, no study has investigated the timing of hypoglycemic events in children with HI. It is important to identify periods of greater risk of hypoglycemia to design targeted detection, prediction, and prevention strategies, as traditional medical management techniques do not allow for this. Hall et al [36], Colas et al [37], and Lunt et al [38] used CGM as a short-term phenotyping tool to better understand patient profiles and categorize risks. Larkin et al [39] detailed their intention to use CGM as part of a long-term phenotyping tool on a large scale to provide personalized insights into disease. 
Digital phenotyping allows for two important changes in disease management. First, the detailed analysis of CGM data provides an extension of the digital phenotype for both the disease and the individual and allows for the targeting of interventions to times when they will achieve the optimum effect. Second, patients and parents are not passive bystanders in the management of HI, and an analysis of how they interact with and respond to the technology further extends the digital phenotype [40], as well as enabling and enhancing behavior change [41]. Knowledge of an extended digital phenotype will not, in and of itself, improve outcomes but does improve understanding of how future interventions can be adapted to achieve the most significant and lasting behavior change [42].

\section{Objective}

In this study, we take the first step in extending the digital phenotype of $\mathrm{HI}$ by describing glycemic trends and identifying the timing of hypoglycemia measured by CGM. The following findings provide a basis for future work concentrating on using the newly extended digital phenotype with human-computer interactions and ultimately altering care behaviors of parents to reduce the incidence of damaging hypoglycemia. Our original code is provided as an appendix (Multimedia Appendix 1) and is freely available on GitHub [43].

\section{Methods}

\section{Recruitment}

Patients were recruited between July 2017 and October 2020. Three distinct groups of patients were enrolled in the study: (1) those with a diagnosis of HI who were in hospital for acute management $(n=6),(2)$ those in an outpatient setting with a diagnosis of $\mathrm{HI}$ and for whom glycemic control was suboptimal $(\mathrm{n}=17)$, and (3) those with a diagnosis of idiopathic ketotic hypoglycemia (IKH) for whom glycemic control was unstable $(n=24)$. The IKH group was selected to investigate CGM profiles in an alternative clinical model of hypoglycemia that does not involve excess insulin secretion. All patients underwent CGM with the primary intention of better understanding their glucose control for clinical purposes. All patients were approached by the research team to seek consent to use anonymized CGM data for research purposes, as per a local research ethics protocol (REC/H1010/88).

Within the HI group, further subcategorization was done as either diffuse or focal disease [44]. Focal HI is characterized by the formation of a focal lesion within the pancreas comprising hyperfunctioning islets and is potentially curative by focal lesionectomy. Diffuse HI implies some specific histopathological features but practically implies nonfocal HI in which medical therapy should be prioritized over surgery when possible.

Patient recruitment to the study was based on a pragmatic design in the absence of previous studies to determine sample size in a rare disease. Previous studies investigating CGM in patients with HI recruited 11 to 15 patients [19,21]. We recruited all patients undergoing CGM for clinical reasons over a 3-year period.

\section{Data collection}

Patients undergoing inpatient monitoring had their CGM device (Dexcom G4 or G6 depending on the date) attached between 1 and 5 days before pancreatic surgery (lesionectomy or subtotal pancreatectomy) and removed after plasma glucose levels stabilized, reducing the need for frequent monitoring. All other patients were brought to the Royal Manchester Children's hospital to have their CGM device attached by a specialist nurse, after which they returned home for the remainder of the monitoring period. The patients returned CGM devices to the department at the end of the monitoring period. CGM devices were always inserted in the daytime to ensure that full calibration had occurred before the evening and data collected overnight were reliable. Data were collected for between 4 and 10 days from each patient.

For patients who underwent a controlled fast in hospital $(n=0$ for $\mathrm{HI}, \mathrm{n}=2$ for $\mathrm{IKH}$ ) during CGM, data during the fasting period were deleted from the analysis and the only data used were those acquired from home monitoring after discharge from hospital. Dexcom G4 devices were used from the beginning of the study period until March 2019, from which point all patients were monitored using a Dexcom G6 device. All devices were unblinded so that parents and staff could see glucose values in real time and alarms would sound if glucose levels dropped (or was predicted to drop) below $3.5 \mathrm{mmol} / \mathrm{L}$ for those with $\mathrm{HI}$ and $3.3 \mathrm{mmol} / \mathrm{L}$ for those with IKH (as per lowest allowable device settings). The fall rate and urgent low soon alarms were set to on when the device was given to the patient. Patient modifications of the alarms were not routinely investigated.

\section{Data Analysis}

Hypoglycemia was defined as any glucose value $<3.5 \mathrm{mmol} / \mathrm{L}$ $(63 \mathrm{mg} / \mathrm{dL})$ as a safe cutoff used by most specialized centers for the everyday management of HI [14]. Dexcom CGM devices report a glucose value every 5 minutes, and therefore, hypoglycemia events were measured at 5-minute intervals with a minimum duration of 5 minutes. The term early hours is used throughout the manuscript to refer to the period 3 AM to 7 AM.

Data were downloaded from CGM devices to Dexcom CLARITY database and raw data were downloaded for analysis using Python 3.8. We analyzed the total number of hypoglycemia events by start time irrespective of length and separately the total amount of time spent in hypoglycemia within each hour period.

As data were not normally distributed, nonparametric tests (Mann-Whitney $U$ ) were used to assess for differences between continuous variables. Chi-square tests were used to assess differences in proportions or percentages between the groups. The results provided are raw test statistics and associated $P$ values.

Glucose testing using alternative methods (plasma glucose measured by point-of-care testing or handheld home glucose monitoring) was not routinely performed alongside CGM because assessment of CGM accuracy was not the intention or focus of this study. Correlations between CGM-derived subcutaneous glucose and plasma glucose have been previously reported in patients with $\mathrm{HI}[19,21]$. 


\section{Results}

\section{Overview}

Baseline data showed a male predominance (29 males, 18 females) and mean age in months at the time of CGM was higher in those with IKH than in those with HI (82, SD 43 vs 57, SD
$61 ; P=.03)$, as expected, given that $\mathrm{HI}$ is prevalent at a younger age than IKH. At the time of CGM testing, the mean time in months from diagnosis did not differ significantly between those with IKH and HI (33, SD 34 vs 49, SD 53; $P=.43$ ) (Table 1). A total of 28 patients underwent monitoring with a Dexcom G4 device and 19 with a Dexcom G6.

Table 1. Demographics of hyperinsulinism and idiopathic ketotic hypoglycemia groups.

\begin{tabular}{|c|c|c|c|}
\hline Demographics & Hyperinsulinism $(\mathrm{N}=23)$ & $\mathrm{IKH}^{\mathrm{a}}(\mathrm{N}=24)$ & $P$ value $^{\mathrm{b}}$ \\
\hline Male, n (\%) & $17(74)$ & $12(50)$ & .09 \\
\hline Female, n (\%) & $6(26)$ & $12(50)$ & $\mathrm{N} / \mathrm{A}^{\mathrm{c}}$ \\
\hline Age (months), mean (SD) & $57(60)$ & $82(43)$ & .03 \\
\hline Time since diagnosis (months), mean (SD) & $49(52)$ & $33(44)$ & .43 \\
\hline
\end{tabular}

aKH: idiopathic ketotic hypoglycemia.

${ }^{\mathrm{b}} P$ value for difference between groups calculated via chi square test for sex and Mann-Whitney $U$ test for continuous values.

${ }^{\mathrm{c}} \mathrm{N} / \mathrm{A}$ : not applicable.

Demographic data demonstrate that the only difference between groups at baseline was that patients with IKH had a higher mean age at time of CGM.

A total of 449 hypoglycemic events (189 in HI and 260 in IKH) were captured over 237 days. The time spent in hypoglycemia was 15,610 out of a total of 342,355 minutes $(4.6 \%)$. The mean duration of hypoglycemic events was 35 (SD 57) minutes and was longer in those with IKH than in those with HI (40 vs 28). Mean lowest glucose per hypoglycemia event was 3.1 (SD 0.37) $\mathrm{mmol} / \mathrm{L}$. The mean number of hypoglycemic events per patient was 9.5 (SD 9.6) with a positive skew to the distribution (Figure 1), illustrating the small number of patients with a very large number of hypoglycemic events. In patients with HI, there were 42 hypoglycemia events lasting more than 30 minutes from 13 separate patients. The mean duration of such prolonged hypoglycemia events was 79 (SD 72) minutes, with a mean lowest glucose of $2.8 \mathrm{mmol} / \mathrm{L}$. The characteristics of patients with HI are shown in Table 2.

Figure 1. Frequency plot of number of hypoglycemia events (hypos) per patient. This plot demonstrates the positive skew to the distribution of hypoglycemic events. Mean number of hypoglycemia events was 9.5 per patient, and median was 6.0 with 6 patients having no episodes of hypoglycemia and 1 patient having more than 30 separate hypoglycemic events. The majority of patients had 5 to 20 hypoglycemic events.

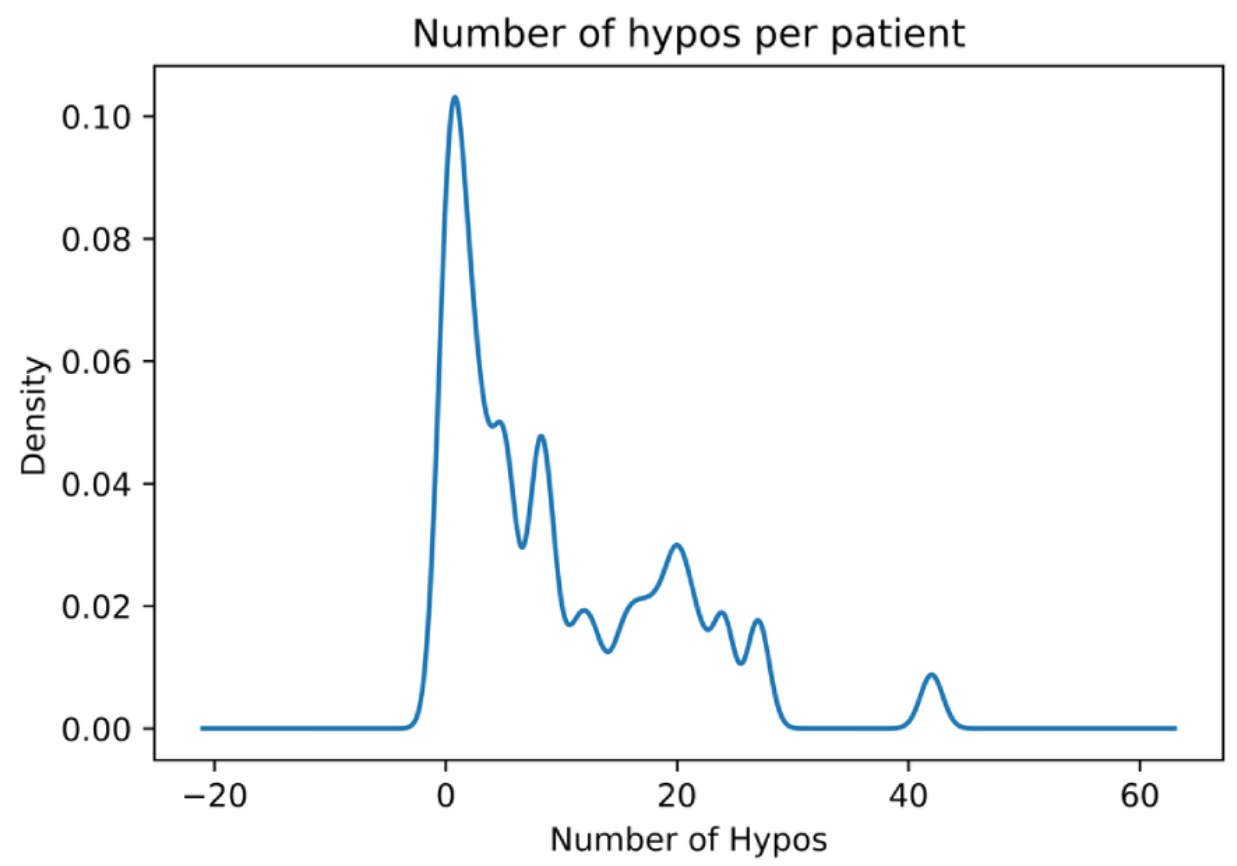


Table 2. Characteristics of patients with hyperinsulinism included in the study. ${ }^{\text {a }}$

\begin{tabular}{|c|c|c|c|c|c|c|c|}
\hline & Sex & Mutation & Type & Surgery & Age (months) & Location & $R x^{b}$ \\
\hline 1 & Male & Not done & Diffuse & None & 88 & Outpatient & None \\
\hline 2 & Male & Not done & Diffuse & None & 8 & Outpatient & None \\
\hline 3 & Female & Negative & Diffuse & None & 92 & Outpatient & None \\
\hline 4 & Male & SLC16A1 & Diffuse & None & 34 & Outpatient & $\mathrm{CHO}^{\mathrm{c}}$ \\
\hline 5 & Male & SLC16A1 & Diffuse & None & 37 & Outpatient & $\mathrm{CHO}^{\mathrm{c}}$ \\
\hline 6 & Female & Negative & Diffuse & None & 119 & Outpatient & None \\
\hline 7 & Male & $A B C C 8$ & Diffuse & None & 58 & Outpatient & Diazoxide \\
\hline 8 & Male & $G C K$ & Diffuse & None & 190 & Outpatient & Diazoxide \\
\hline 9 & Male & $A B C C 8$ & Diffuse & Subtotal $^{\mathrm{d}}$ & 141 & Outpatient & None \\
\hline 10 & Male & $A B C C 8$ & Diffuse & Subtotal $^{\mathrm{d}}$ & 132 & Outpatient & None \\
\hline 11 & Male & $A B C C 8$ & Focal & Lesionectomy & 2 & Inpatient & Octreotide \\
\hline 12 & Male & $A B C C 8$ & Diffuse & None & 36 & Outpatient & None \\
\hline 13 & Female & $A B C C 8$ & Diffuse & Subtotal $^{\mathrm{d}}$ & 51 & Outpatient & Octreotide \\
\hline 14 & Male & $A B C C 8$ & Focal & Lesionectomy & 36 & Outpatient & Octreotide \\
\hline 15 & Female & Negative & Diffuse & None & 17 & Outpatient & Diazoxide \\
\hline 16 & Female & $A B C C 8$ & Focal & Lesionectomy & 3 & Inpatient & Octreotide \\
\hline 17 & Male & Negative & Diffuse & None & 63 & Outpatient & Diazoxide \\
\hline 18 & Male & Negative & Diffuse & None & 10 & Outpatient & Diazoxide \\
\hline 19 & Male & $A B C C 8$ & Diffuse & Subtotal $^{\mathrm{d}}$ & 193 & Outpatient & None \\
\hline 20 & Male & $A B C C 8$ & Focal & Lesionectomy & 1 & Inpatient & None \\
\hline 21 & Male & $A B C C 8$ & Focal & Lesionectomy & 3 & Inpatient & Octreotide \\
\hline 22 & Female & $A B C C 8$ & Focal & Lesionectomy & 1 & Inpatient & Octreotide \\
\hline 23 & Male & $A B C C 8$ & Focal & Lesionectomy & 3 & Inpatient & Octreotide \\
\hline
\end{tabular}

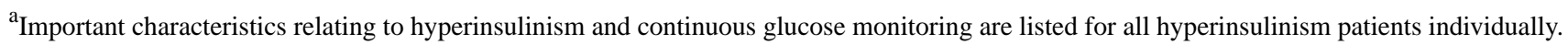

${ }^{\mathrm{b}} \mathrm{Rx}$ : medical treatment at the time of continuous glucose monitoring.

${ }^{\mathrm{c}} \mathrm{CHO}$ : carbohydrate supplementation in feeds.

${ }^{\mathrm{d}}$ Subtotal: subtotal pancreatectomy.

\section{Timings of Hypoglycemia in Patients With HI}

Figure 2 presents the number of hypoglycemic events by start time in patients with HI $(n=23)$. This does not account for the duration of hypoglycemia episodes and is only representative of the hour in which the event started. There was a higher risk of a hypoglycemia event beginning in the later part of the night/early morning compared with the rest of the day. Figure 3 illustrates the percentage of time spent in hypoglycemia by patients with HI within each hour of the day. There was an increase in the prevalence of hypoglycemia in the early hours (3 AM-7AM), 6.4\% (1665/25,875 minutes) of this time hypoglycemic compared with only $2.9 \%$ (3585/123,490 minutes) of time outside this period $\left(\chi_{1}^{2}=98.4, P<.001\right)$. This represents a doubling of risk during this period. Although the frequency of hypoglycemia was greater in the early hours, the mean duration (minutes) of individual hypoglycemic episodes in this period was the same as the rest of the day (28.2 minutes vs 28.1 minutes, $P=.99$ ). 
Figure 2. Number of hypoglycemic events (hypos) plotted by start time in patients with HI. The X-axis represents hours of each 24 hour period. Bars represent the number of hypoglycemic events starting at any particular point in the day but do not indicate the duration of each episode. What is demonstrated is the increased number of hypoglycemic episodes starting in the later hours of the night and early morning (black) compared with the rest of the day (grey). HI: hyperinsulinism.

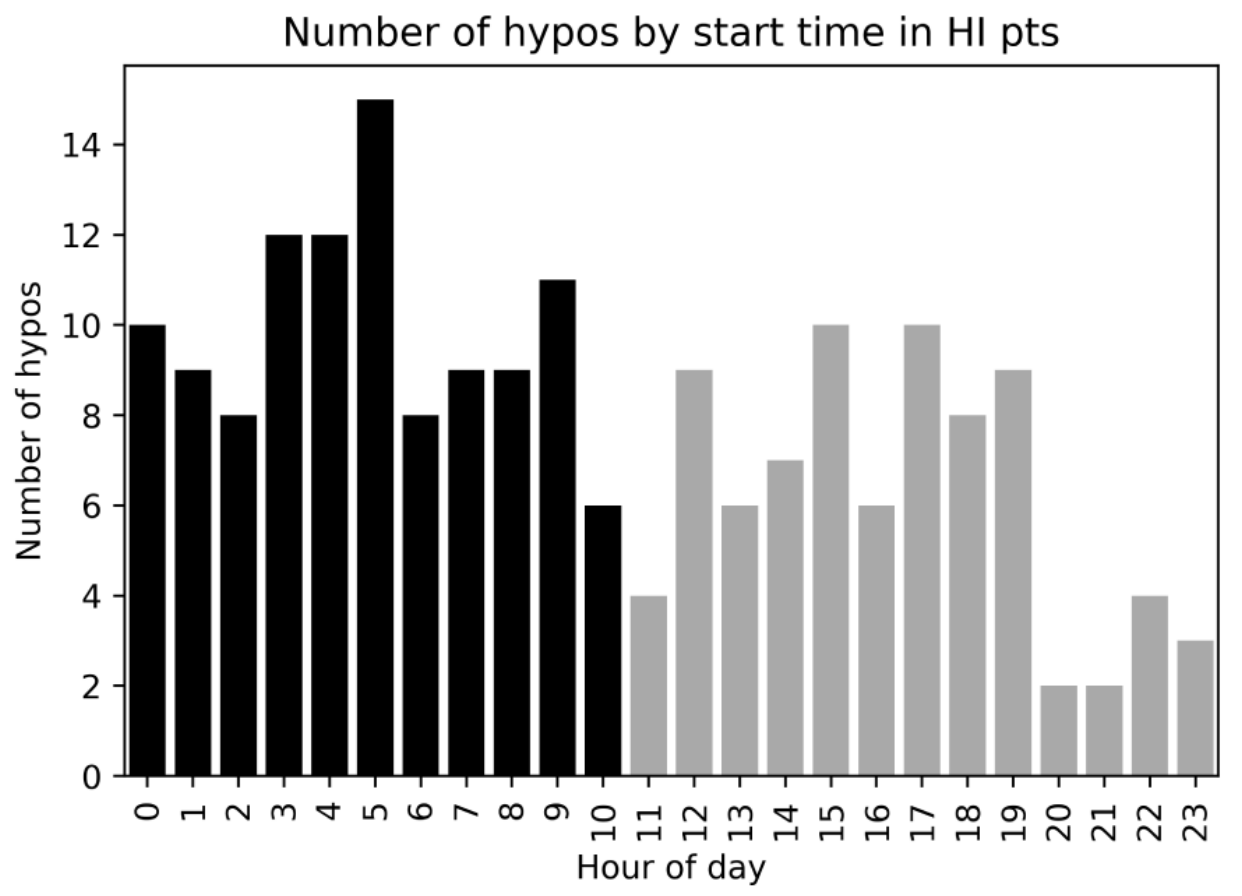

Figure 3. Percentage time spent in hypoglycemia by hour of the day in patients with HI.There is a clear period of high risk for hypoglycemia between $3 \mathrm{AM}$ and $7 \mathrm{AM}$ (dark blue) which represents the early hours. There are also three distinct spikes of increased hypoglycemia prevalence at 9 AM, 3 PM and 7 PM (orange), which may represent postprandial hypoglycemia. HI: hyperinsulinism.

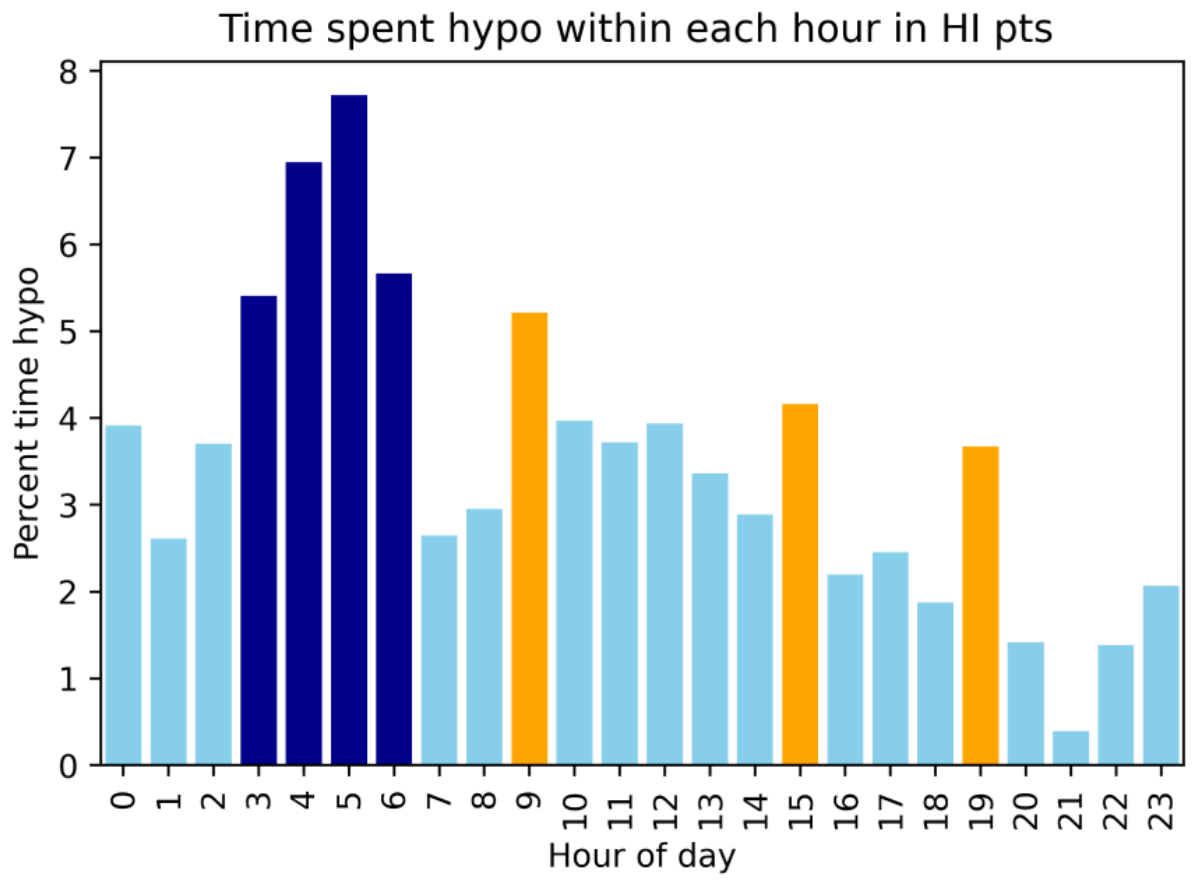

The other periods of increased risk were the separate hours of 9 AM, 3 PM, and 7 PM, within which there was a higher proportion of minutes spent hypoglycemic than the rest of the daytime/evening (7 AM to midnight), that is 5.2\% (320/6140 minutes), $4.2 \%$ (250/6015 minutes), and 3.7\% (230/6265 minutes), respectively, versus $2.8 \%$ (2915/103,910 minutes; $P<.001)$.

\section{Subgroup Analysis of Patients With HI}

Analysis of time spent in hypoglycemia by patients with HI above $(n=16)$ and below $(n=7)$ the age of 10 months (ie, the age at which a weaning diet with solid food is well established) demonstrated that the risk of early hours of hypoglycemia was even more pronounced in the group above the age of 10 months (Figure 4). Within the early hours, 7.6\% (1480/19,370 minutes) 
of the time was hypoglycemic compared with $2.6 \%$ (2405/92,840 minutes) of time outside of this period $\left(\chi_{1}^{2}=146.4\right.$, $P<.001)$, indicating an almost trebling risk of hypoglycemia. In the group below the age of 10 months, no obvious patterns of hypoglycemia were visible with risk of hypoglycemia distributed randomly throughout the day, except for an unexplained peak of risk at 7 PM (Figure 5).

Figure 4. Percentage time spent hypoglycemic by hour of the day in patients with $\mathrm{HI}>10$ months of age. Analysis of timings of hypoglycemia in this subgroup show a greater tendency to early hours hypoglycemia between the hours of 3 AM and 7 PM (dark blue) with a persistence of spikes in hypoglycemia risk at 9 AM and 3 PM (orange). No spike is observed at 7 PM in contrast to the analysis for all ages. HI: hyperinsulinism.

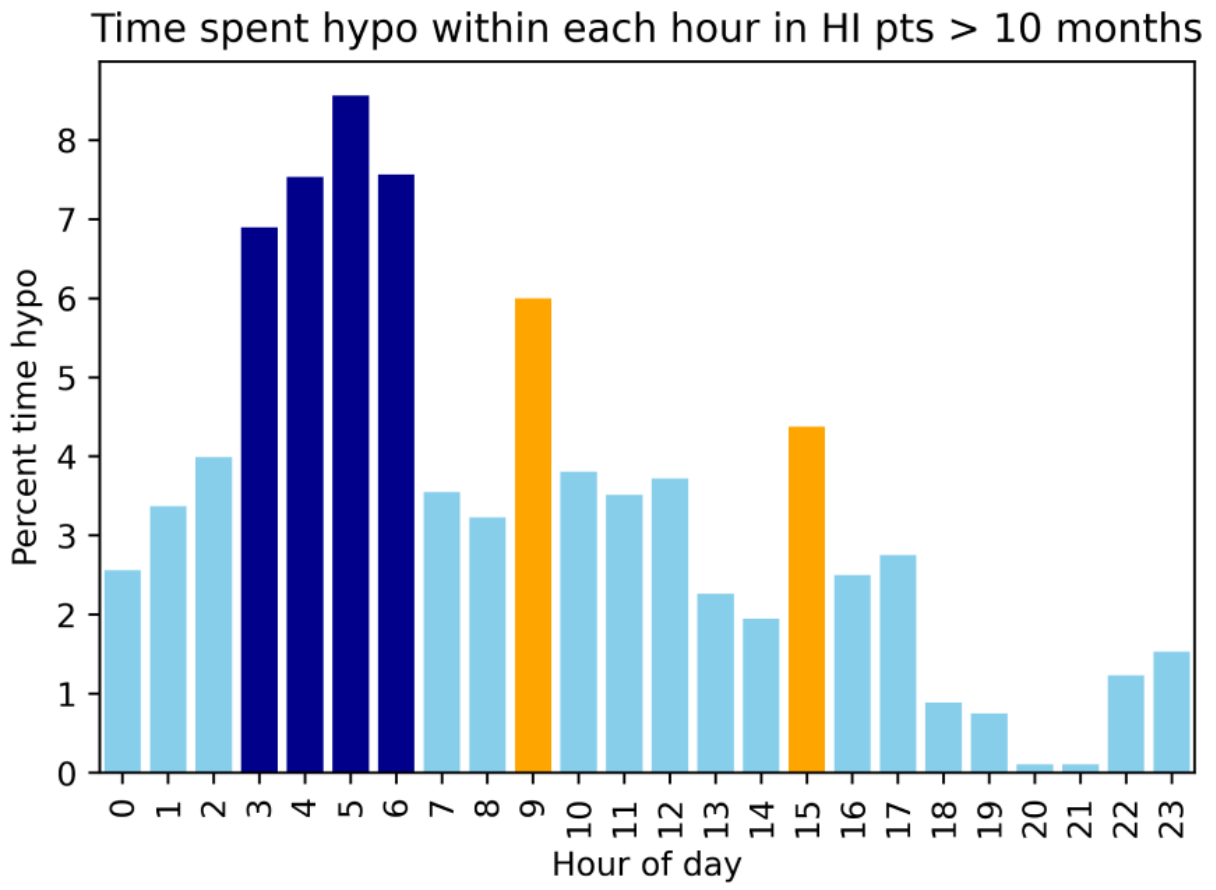

Figure 5. Percentage time spent hypoglycemic by hour of the day in patients with $\mathrm{HI}<10$ months of age. Analysis of timings of hypoglycemia in this subgroup are limited by numbers but clearly show a very different pattern of hypoglycemia compared with the group >10 months of age. There is no obvious pattern of hypoglycemia and no obvious periods of higher risk. HI: hyperinsulinism.

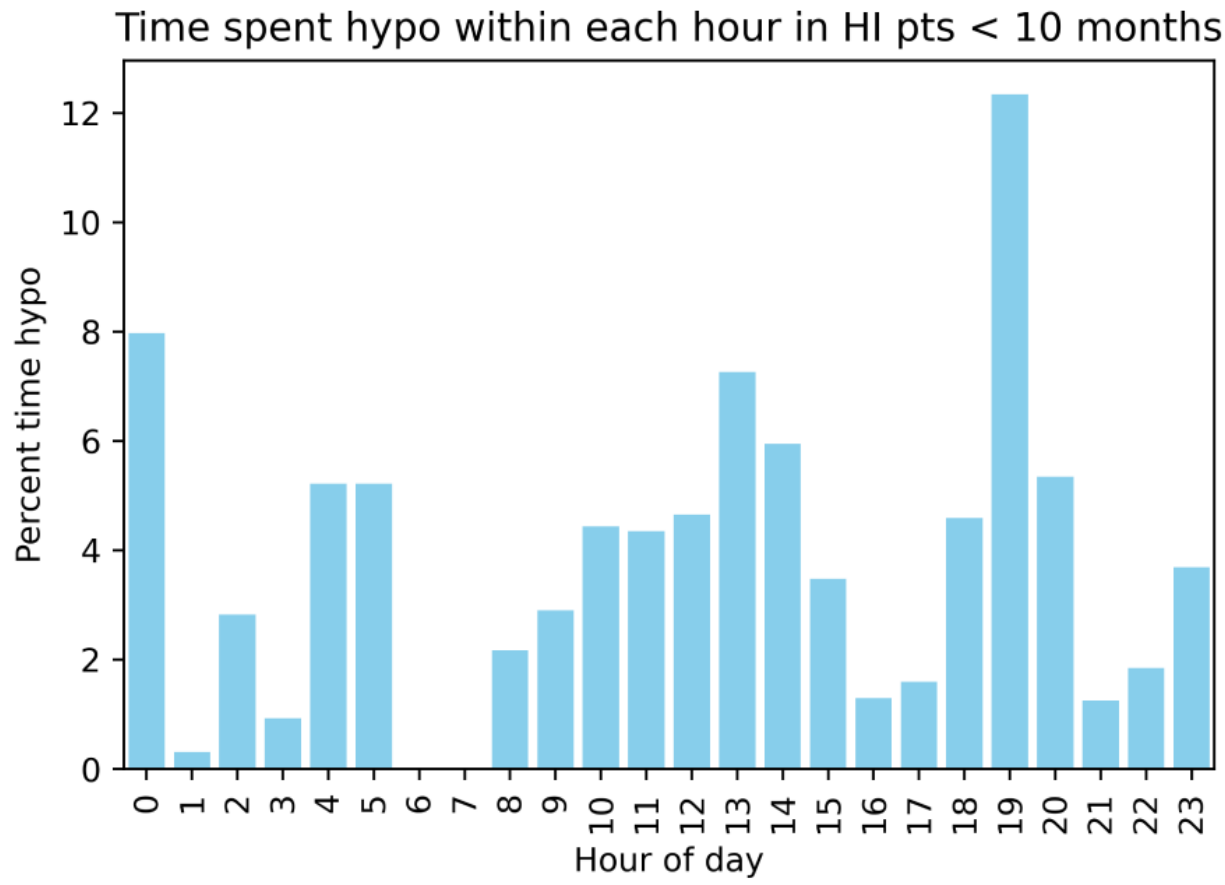

Further comparisons were performed between the following HI subgroups: mutation-positive versus mutation-negative and medication versus off-medication. The results are summarized in Table 3 and reported in more detail (along with Figures S1-S4) in Multimedia Appendix 2: further HI subgroup comparisons. 
Table 3. Comparisons of timings of hypoglycemia between hyperinsulinism (HI) subgroups. ${ }^{\text {a }}$

\begin{tabular}{|c|c|c|c|c|c|c|c|}
\hline & \multicolumn{2}{|c|}{$\begin{array}{l}\text { Time hypoglycemic in early } \\
\text { hours (minutes) }\end{array}$} & \multicolumn{2}{|c|}{$\begin{array}{l}\text { Time hypoglycemic outside early } \\
\text { hours (minutes) }\end{array}$} & \multicolumn{2}{|c|}{$\begin{array}{l}\text { Minutes hypo contained in early } \\
\text { hours (expected } 16.7 \% \text {; minutes) }\end{array}$} & \multirow[t]{2}{*}{$\begin{array}{l}\text { Period of risk (compared } \\
\text { with all HI) }\end{array}$} \\
\hline & Total, $\mathrm{N}$ & Value, n (\%) & Total, N & Value, $\mathrm{n}(\%)$ & Total, N & Value, $\mathrm{n}(\%)$ & \\
\hline All HI & 25,875 & $1665(6.43)$ & 123,490 & 3585 (2.9) & 5250 & $1665(31.71)$ & Early hours \\
\hline \multicolumn{8}{|c|}{ Age (months), mean (SD) } \\
\hline$>10$ & 19,370 & $1480(7.64)$ & 92,840 & $2405(2.59)$ & 3885 & $1480(38.09)$ & Early hours $++^{b}$ \\
\hline$<10$ & 6505 & $185(2.84)$ & 37,150 & $1365(3.85)$ & 1365 & $185(13.55)$ & Evenly distributed \\
\hline \multicolumn{8}{|c|}{ HI causing mutation } \\
\hline Positive & 17,005 & $1135(6.67)$ & 81,810 & $2290(2.79)$ & 3425 & $1135(33.14)$ & Early hours $+^{\mathrm{c}}$ \\
\hline Negative & 8870 & $530(5.98)$ & 41,680 & $1295(3.11)$ & 1825 & $530(29.04)$ & Early hours - ${ }^{\mathrm{d}}$ \\
\hline \multicolumn{8}{|l|}{ Medication } \\
\hline On & 14,415 & $790(5.48)$ & 69,485 & $2395(3.45)$ & 3185 & $790(24.8)$ & Early Hours -- e \\
\hline Off & 11,460 & $875(7.64)$ & 54,005 & $1190(2.2)$ & 2065 & $875(42.37)$ & Early Hours ++ \\
\hline
\end{tabular}

${ }^{\text {a }}$ Detailed is the difference in percentage time hypoglycemic in the early hours (3 AM-7 AM). Also reported is the percentage of all hypoglycemia minutes spent in the early hours as a comparison to the expected $16.7 \%$ that would be seen if hypoglycemia was distributed evenly. The table demonstrates an exaggerated tendency to hypoglycemia at early hours in those above the age of 10 months, off medication, and with a known hyperinsulinism causing mutation.

$\mathrm{b}_{++}$is used to denote a very strong tendency to early hours hypoglycemia.

${ }^{c}+$ is used to denote a strong tendency to early hours hypoglycemia.

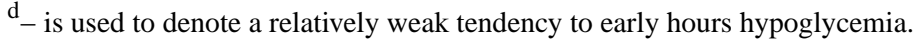

e -- is used to denote a weak tendency to early hours hypoglycemia.

\section{Timings of Hypoglycemia in Those With IKH}

The timing of hypoglycemia in patients with IKH showed a more evenly distributed pattern than in those with HI. The number of hypoglycemic episodes starting overnight was slightly higher than that during the day (Figure 6), but not as markedly as in the patients with HI. Total minutes spent hypoglycemic were also more evenly distributed throughout the day in patients with IKH than in those with HI (Figure 7). There was no clear period of higher than average risk of hypoglycemia; rather, a period of relatively low risk was observed in the evening and early night (6 PM-1 AM). Within this period, the risk of hypoglycemia was $2.8 \%(1575 / 57,195$ minutes $)$ compared with $6.5 \%(8785 / 135,805$ minutes $)$ outside of this period $\left(\mathrm{X}^{2}{ }_{1}=132.2\right.$, $P<.001)$.

Subgroup analysis of patients with IKH was not performed, as no patients within this group were below the age of 10 months and this group was primarily analyzed as a comparison group for those with HI. 
Figure 6. Number of hypoglycemic events (hypos) plotted by hour of the day in patients with IKH. This demonstrates the risk of a hypoglycemic event starting at any particular point in the day but does not account for the length of this episode. An increased number of hypoglycemic episodes starting in the later hours of the night and early morning (dark blue) is observed, compared with the rest of the day (light blue). This, however, is less pronounced than in those patients with HI. HI: hyperinsulinism; IKH: idiopathic ketotic hypoglycemia.

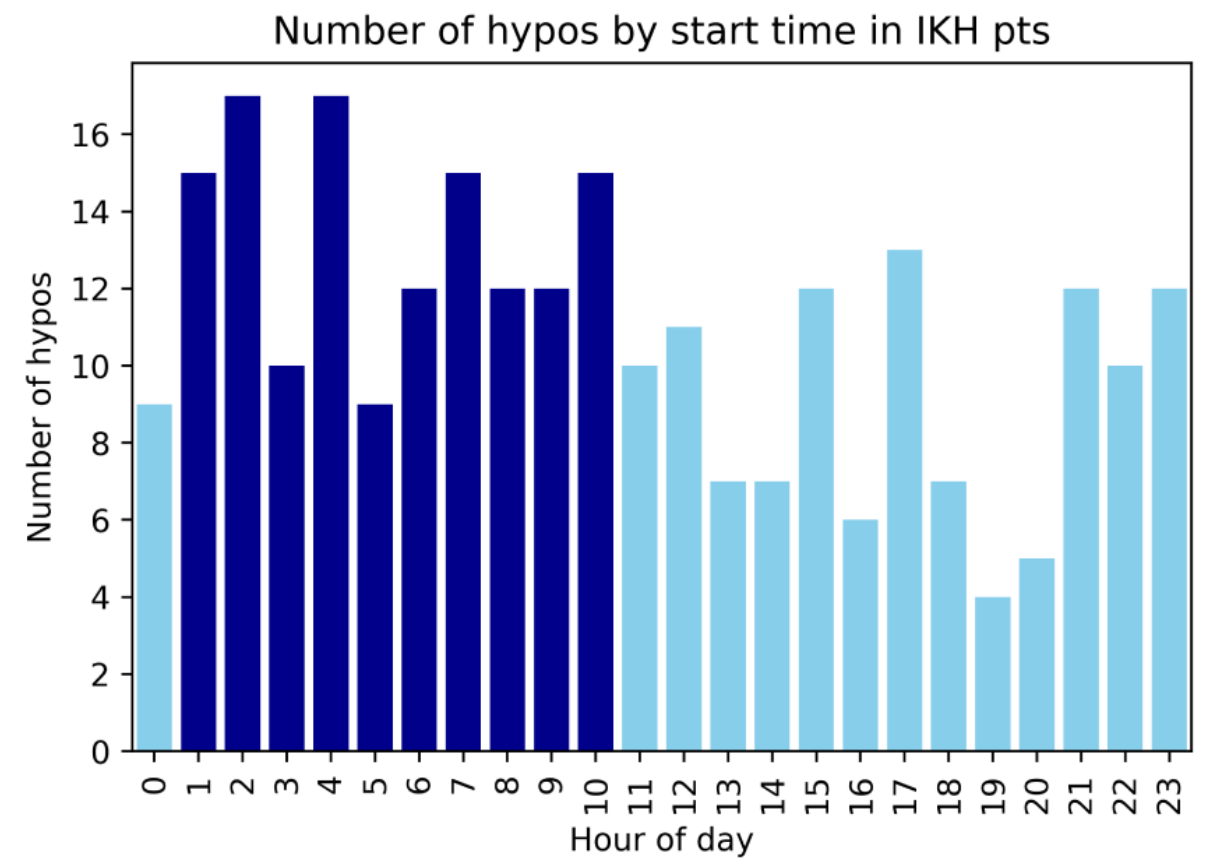

Figure 7. Percentage time hypoglycemic by hour of the day in patients with IKH. There is no period of particularly high risk as seen in patients with HI. In contrast, a short period of lower than average risk in the evening and early night (green) can be observed. HI: hyperinsulinism; IKH: idiopathic ketotic hypoglycemia.

\section{Time spent hypo within each hour in IKH pts}

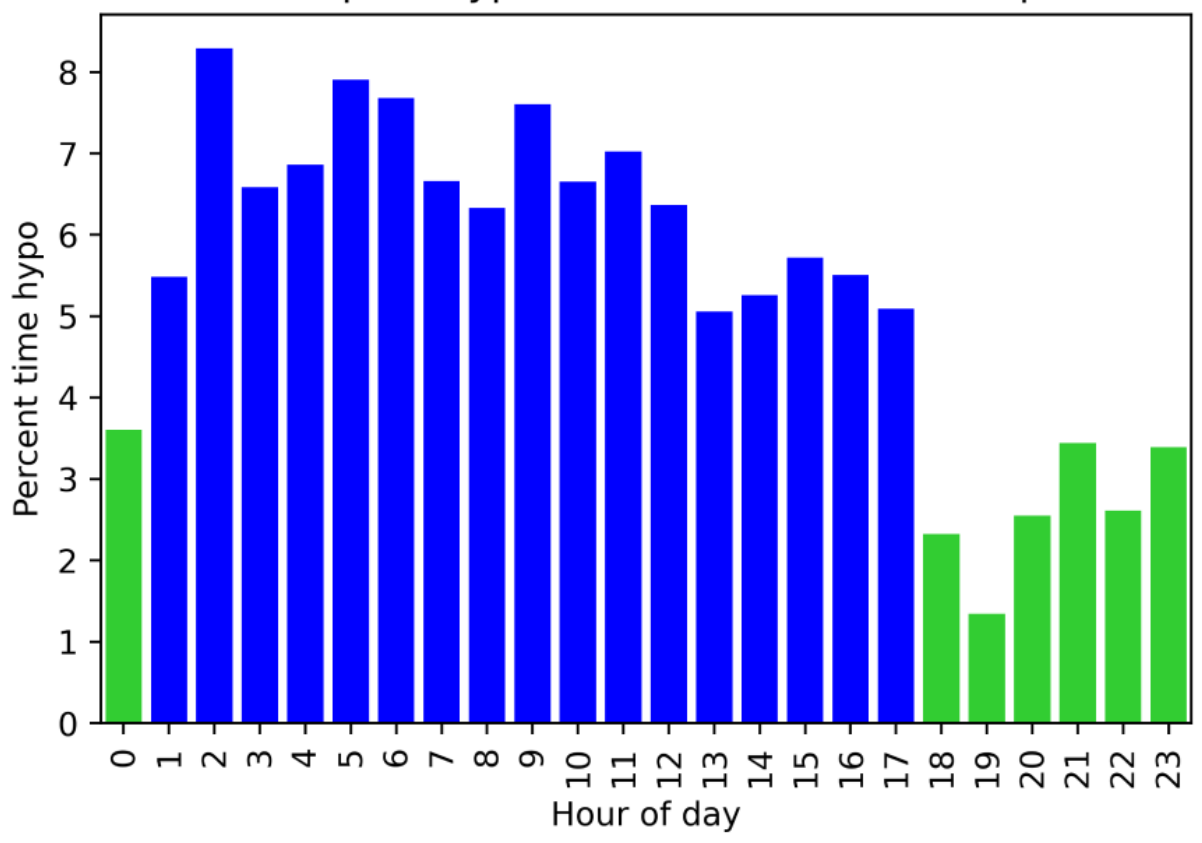

\section{Altering Thresholds for Hypoglycemia}

As the definition of hypoglycemia differs between countries, regions, and even hospital departments, we performed further analysis by altering the threshold for hypoglycemia. The cutoffs of $3.9 \mathrm{mmol} / \mathrm{L}, 3.5 \mathrm{mmol} / \mathrm{L}$, and $3.0 \mathrm{mmol} / \mathrm{L}$ were chosen as commonly used definitions for hypoglycemia in children $[44,45]$. Further analysis of values below this were deemed unlikely to be meaningful as they are rare events, and the Dexcom CGM devices only measure glucose down to 2.2 $\mathrm{mmol} / \mathrm{L}$, below which values are reported as Low.

Data for HI patients above the age of 10 months were compared with those of patients with IKH, as these 2 groups were more comparable in terms of age. As hypoglycemia threshold was reduced from $3.9 \mathrm{mmol} / \mathrm{L}$ to $3.5 \mathrm{mmol} / \mathrm{L}$ and then $3.0 \mathrm{mmol} / \mathrm{L}$, 
the tendency to hypoglycemia during early hours was emphasized in patients with HI. In patients with HI, the early hours contained $41 \%$ of all minutes (63/152 minutes) spent with a glucose level $<3.0 \mathrm{mmol} / \mathrm{L}$ despite this period representing only $16.7 \%$ of the 24 -hour period. A similar trend began to emerge in patients with IKH when the hypoglycemia threshold was reduced, and the proportion of all minutes spent hypoglycemic that lay within the early hours increased from $21 \%$ (842/3998 minutes) to $27 \%$ (157/577 minutes). Figures S5 and S6 provide a visualisation of this change and are provided in Multimedia Appendix 3.

\section{Discussion}

\section{Principal Findings}

We have provided a novel analysis of the timing of hypoglycemic events in patients with HI using CGM data. Our data provide new and clinically useful information to extend the digital phenotype of HI. This aspect of the newly described digital phenotype demonstrates a tendency for hypoglycemia during the early hours ( $3 \mathrm{AM}-7 \mathrm{AM}$ ) where the risk is 2 to 3 times higher than that at other times of the day. The relative risk of nocturnal hypoglycemia compared with daytime hypoglycemia was greater in patients with $\mathrm{HI}$ than in those with $\mathrm{IKH}$. This risk is greater still in patients with $\mathrm{HI}$ above the age of 10 months, those with genetic mutations, and those off medication.

A strength of this study is the novel examination of a glycemic phenotype using CGM in patients with HI while using an alternative model of hypoglycemia in children with IKH as a contrasting paradigm, demonstrating the specificity of glycemic profiles within each condition's digital phenotype. Although home blood glucose monitoring remains the standard of care for monitoring in patients with $\mathrm{HI}$, we have used high-granularity glucose data to expand the phenotype of $\mathrm{HI}$ and highlight an important role for CGM, that is, describing nocturnal glycemic status in real time with high ecological validity. Alternative strategies to identify periods of hypoglycemia on the basis of parent interviews would be open to recall bias and unable to identify unexpected hypoglycemia, as self-monitoring of blood glucose is rarely performed overnight. With increasing refinements in CGM technology and the increasing popularity of the use of CGM in children with hypoglycemia, our study highlights the need for a targeted application of CGM. Although previous studies have used simplistic correlation methods to test the accuracy of CGM in the detection of hypoglycemia vis-à-vis home blood glucose monitoring, our study has investigated a deeper phenotype with significant clinical impact.

Our study is exploratory, as a similar analysis of CGM data has never been attempted. Therefore, it is not possible to validate the strength of our observations, except that the glycemic phenotype is replicable across the whole group with HI, in contrast to an alternative model of hypoglycemia in IKH. The number of patients with $\mathrm{HI}$ was large for a rare disease, and the total number of measurements in the data set adds strength to the rigor of the study.
It is not possible to investigate the cause of early hours hypoglycemia from the design of our study, nor was this the intended purpose. We speculate that the unavailability of carbohydrates due to the nocturnal fasting period, high glucose demand in the brain at this time [23,31], and the suppression of counter-regulatory gluconeogenesis in patients with HI [30] could be the probable causes. The latter view is supported by the observation of a reduced tendency to early hours hypoglycemia in patients with IKH and an increased tendency in those positive for genetic mutations known to cause HI. Patients with IKH do not have underlying metabolic disturbances and are therefore capable of mounting adequate counter-regulatory responses. In contrast, those positive for $\mathrm{HI}$ mutations tend to have more severe disease [11] and less ability to mount counter-regulatory responses. Further investigation of the metabolic and counter-regulatory hormonal milieu in patients with HI may be required to refine specific causation. It is not clear why patients negative for mutations had a relatively high incidence of hypoglycemia between 9 PM and $1 \mathrm{AM}$, and further work will be required to investigate this apparent trend.

We observed a tendency for early hours hypoglycemia in patients with HI above the age of 10 months (Figure 4); this may be explained by older children sleeping longer and requiring less frequent feeds through the night. We did not record sleep-wake cycles in our study to confirm or refute this possibility. However, children below the age of 10 months were also more likely to be inpatients during the period of monitoring, and the lack of early hours hypoglycemia tendency may reflect 24-hour nursing care and a reduction in ecological validity. The reason for the significant increase in time spent in hypoglycemia between 7 PM and 8 PM is unclear and may reflect the small number of patients from whom this sample was taken. Further data are required to validate or refute this finding.

Patients with HI who were no longer receiving HI medications showed a clear tendency toward hypoglycemia during early hours seen in other groups. This response was not observed in patients receiving medications for $\mathrm{HI}$ (diazoxide or octreotide). This may reflect the efficacy of HI medications in preventing nocturnal hypoglycemia but may also be simply reflective of the much higher median age in the off-treatment group and the subsequent effects described above. Because this study was completed, it was not possible to assess the relative impacts of age and medication on the timing of hypoglycemia in patients with HI, and further work is required.

Tendency to hypoglycemia was shown to reduce throughout the day in patients with HI, but with small increase in risk at 9 AM, 3 PM, and 7 PM (Figure 3). These periods of increased risk are likely to correlate with postmeal times in those having three meals a day, suggesting possible postprandial hypoglycemia secondary to the hyperinsulinemic response to food sometimes observed in patients with HI [46]. This trend was not observed in patients with IKH who had fasting rather than postprandial hypoglycemia. This was not observed in patients with $\mathrm{HI}$ below the age of 10 months who would have been receiving a high proportion of caloric intake as milk feeds distributed more frequently throughout the day and night. 
As hypoglycemia thresholds were reduced from $3.9 \mathrm{mmol} / \mathrm{L}$ to $3.5 \mathrm{mmol} / \mathrm{L}$ and $3.0 \mathrm{mmol} / \mathrm{L}$, the number of hypoglycemic events and total minutes spent hypoglycemic also reduced significantly, as reflected in the differing $\mathrm{Y}$ axes in Figures S5 and S6 (Multimedia Appendix 3). This is unsurprising, as patients with $\mathrm{HI}$ are told to maintain glucose levels $>3.5 \mathrm{mmol} / \mathrm{L}$ and those with $\mathrm{IKH}>3.0 \mathrm{mmol} / \mathrm{L}$. Reducing the hypoglycemia threshold emphasized the tendency for early hours hypoglycemia in those with $\mathrm{HI}$ and allowed it to become apparent in those with IKH. These likely better reflect the true hypoglycemic events that would be acted on by parents.

There were 42 hypoglycemia events lasting more than 30 minutes in patients with $\mathrm{HI}$ despite them wearing an unblinded CGM device programmed to alarm at glucose levels $<3.5$ $\mathrm{mmol} / \mathrm{L}$ and parents being aware of the importance of keeping glucose levels $\geq 3.5 \mathrm{mmol} / \mathrm{L}$ at all times. This high prevalence of prolonged and potentially dangerous hypoglycemia events may reflect CGM inaccuracy, and these events may represent false positives not acted on by parents. However, this is unlikely to explain all the prolonged hypoglycemic events.

Although CGM provides vital information, the volume of data provided by continuous monitoring such as CGM can be overwhelming for both health care professionals and patients [47], and simple detection and reporting of glucose values will not be sufficient to eliminate all hypoglycemia. It is well recognized that alarm fatigue is a significant problem [48] and that only $37 \%$ of parents will wake to hypoglycemia alarms that sound overnight [49]. Other behavioral explanations are possible, including voluntary alarm switching off and leaving the receiver out of earshot. The engagement of parents with the CGM device and their behaviors in response to data provided comprise a vital extension of the digital phenotype of HI [40,42].

Future work must further evaluate this aspect of the digital phenotype of HI to better understand not only the underlying pathophysiology but also the human in the loop. Simple mathematical modeling to generate ever better glycemic predictions is unable to eradicate hypoglycemic events in the real world if it does not factor in how human behaviors change in response to the data.

\section{Conclusion}

We provide the first analysis of the timing of hypoglycemia in patients with hypoglycemia due to HI using CGM data and, in doing so, expand the digital phenotype. In contrast to the phenotype of hypoglycemia in children with IKH, a clear period of high risk for hypoglycemia was observed in patients with $\mathrm{HI}$ in the early hours (3 AM-7 AM). Such early hours hypoglycemia was particularly frequent in those with genetic mutations known to cause HI and in children older than 10 months. Despite the unblinded state-of-the-art technology, prolonged and potentially harmful hypoglycemic events were detected in patients with HI. Hypoglycemia during early hours poses a high risk for neuroglycopenic brain injury, and behavioral aspects of the digital phenotype in HI must be evaluated so that interventions can be designed to maximize effect.

\section{Conflicts of Interest}

None declared.

\section{Multimedia Appendix 1}

Notepad file with original Python code used for data analysis. This can also be found freely available on GitHub $[<x$ ref ref-type="bibr" rid="ref49" $>49</$ xref $>$ ].

[TXT File, $10 \mathrm{~KB}-$ Multimedia Appendix 1]

\section{Multimedia Appendix 2}

Further hyperinsulinism subgroup comparisons.

[DOC File, 302 KB-Multimedia Appendix 2]

\section{Multimedia Appendix 3}

Comparison of reducing hypoglycemia thresholds. [DOC File, $130 \mathrm{~KB}$-Multimedia Appendix 3]

\section{References}

1. Yau D, Laver T, Dastamani A, Senniappan S, Houghton JA, Shaikh G, et al. Using referral rates for genetic testing to determine the incidence of a rare disease: the minimal incidence of congenital hyperinsulinism in the UK is 1 in $28,389$. PLoS One 2020 Feb 06;15(2):e0228417 [FREE Full text] [doi: 10.1371/journal.pone.0228417] [Medline: 32027664]

2. Lord K, Radcliffe J, Gallagher PR, Adzick NS, Stanley CA, De León DD. High risk of diabetes and neurobehavioral deficits in individuals with surgically treated hyperinsulinism. J Clin Endocrinol Metab 2015 Nov;100(11):4133-4139 [FREE Full text] [doi: 10.1210/jc.2015-2539] [Medline: 26327482]

3. Avatapalle HB, Banerjee I, Shah S, Pryce M, Nicholson J, Rigby L, et al. Abnormal neurodevelopmental outcomes are common in children with transient congenital hyperinsulinism. Front Endocrinol (Lausanne) 2013 May 20;4:60 [FREE Full text] [doi: 10.3389/fendo.2013.00060] [Medline: 23730298] 
4. Tam EW, Haeusslein LA, Bonifacio SL, Glass HC, Rogers EE, Jeremy RJ, et al. Hypoglycemia is associated with increased risk for brain injury and adverse neurodevelopmental outcome in neonates at risk for encephalopathy. J Pediatr 2012 Jul;161(1):88-93 [FREE Full text] [doi: 10.1016/j.jpeds.2011.12.047] [Medline: 22306045]

5. Lucas A, Morley R, Cole TJ. Adverse neurodevelopmental outcome of moderate neonatal hypoglycaemia. BMJ 1988 Nov 19;297(6659):1304-1308 [FREE Full text] [doi: 10.1136/bmj.297.6659.1304] [Medline: 2462455]

6. McQuarriei I. Idiopathic spontaneously occurring hypoglycemia in infants; clinical significance of problem and treatment. AMA Am J Dis Child 1954 Apr;87(4):399-428. [Medline: 13147532]

7. Craigie RJ, Salomon-Estebanez M, Yau D, Han B, Mal W, Newbould M, et al. Clinical diversity in focal congenital hyperinsulinism in infancy correlates with histological heterogeneity of islet cell lesions. Front Endocrinol (Lausanne) 2018 Oct 17;9:619 [FREE Full text] [doi: 10.3389/fendo.2018.00619] [Medline: 30386300]

8. Kane C, Shepherd RM, Squires PE, Johnson PR, James RF, Milla PJ, et al. Loss of functional KATP channels in pancreatic beta-cells causes persistent hyperinsulinemic hypoglycemia of infancy. Nat Med 1996 Dec;2(12):1344-1347. [doi: 10.1038/nm1296-1344] [Medline: 8946833]

9. Dunne MJ, Kane C, Shepherd RM, Sanchez JA, James RF, Johnson PR, et al. Familial persistent hyperinsulinemic hypoglycemia of infancy and mutations in the sulfonylurea receptor. N Engl J Med 1997 Mar 06;336(10):703-706. [doi: 10.1056/NEJM199703063361005] [Medline: 9041101]

10. Stanley CA. Perspective on the genetics and diagnosis of congenital hyperinsulinism disorders. J Clin Endocrinol Metab 2016 Mar;101(3):815-826 [FREE Full text] [doi: 10.1210/jc.2015-3651] [Medline: 26908106]

11. Worth C, Hashmi LA, Yau D, Salomon-Estebanez M, Ruiz DP, Hall C, et al. Longitudinal Auxological recovery in a cohort of children with Hyperinsulinaemic Hypoglycaemia. Orphanet J Rare Dis 2020 Jun 24;15(1):162 [FREE Full text] [doi: 10.1186/s13023-020-01438-0] [Medline: $\underline{\text { 32580746] }}$

12. Dawkins R. The Selfish Gene, 1st Edition. London: Oxford University Press; 1976.

13. Jain SH, Powers BW, Hawkins JB, Brownstein JS. The digital phenotype. Nat Biotechnol 2015 May;33(5):462-463. [doi: 10.1038/nbt.3223] [Medline: 25965751]

14. Worth C, Yau D, Estebanez MS, O'Shea E, Cosgrove K, Dunne M, et al. Complexities in the medical management of hypoglycaemia due to congenital hyperinsulinism. Clin Endocrinol (Oxf) 2020 May;92(5):387-395. [doi: 10.1111/cen.14152] [Medline: $\underline{31917867]}$

15. Jauch-Chara K, Schultes B. Sleep and the response to hypoglycaemia. Best Pract Res Clin Endocrinol Metab 2010 Oct;24(5):801-815. [doi: 10.1016/j.beem.2010.07.006] [Medline: 21112027]

16. Torous J, Onnela J, Keshavan M. New dimensions and new tools to realize the potential of RDoC: digital phenotyping via smartphones and connected devices. Transl Psychiatry 2017 Mar 07;7(3):e1053 [FREE Full text] [doi: 10.1038/tp.2017.25] [Medline: 28267146]

17. Worth C, Dunne M, Ghosh A, Harper S, Banerjee I. Continuous glucose monitoring for hypoglycaemia in children: perspectives in 2020. Pediatr Diabetes 2020 Aug;21(5):697-706. [doi: 10.1111/pedi.13029] [Medline: 32315515]

18. Skinner AL, Attwood AS, Baddeley R, Evans-Reeves K, Bauld L, Munafò MR. Digital phenotyping and the development and delivery of health guidelines and behaviour change interventions. Addiction 2017 Jul;112(7):1281-1285. [doi: 10.1111/add.13746] [Medline: 28472848]

19. Rayannavar A, Elci O, Mitteer L, De León DD. Continuous glucose monitoring systems: are they useful for evaluating glycemic control in children with hyperinsulinism? Horm Res Paediatr 2019;92(5):319-327 [FREE Full text] [doi: 10.1159/000506230] [Medline: 32208390]

20. Saif M, Kapoor A, Kochar I, Jindal R. Continuous glucose monitoring system for congenital hyperinsulinemia. Indian Pediatr 2013 Apr 25;50(4):421-422. [doi: 10.1007/s13312-013-0103-3] [Medline: 23665604]

21. Alsaffar H, Turner L, Yung Z, Didi M, Senniappan S. Continuous flash glucose monitoring in children with congenital hyperinsulinism; first report on accuracy and patient experience. Int J Pediatr Endocrinol 2018;2018:3 [FREE Full text] [doi: 10.1186/s13633-018-0057-2] [Medline: 29599801]

22. Braune K, Wäldchen M, Raile K, Hahn S, Ubben T, Römer S, et al. Open-source technology for real-time continuous glucose monitoring in the neonatal intensive care unit: case study in a neonate with transient congenital hyperinsulinism. J Med Internet Res 2020 Dec 04;22(12):e21770 [FREE Full text] [doi: 10.2196/21770] [Medline: 33275114]

23. Kalsbeek A, la Fleur S, Fliers E. Circadian control of glucose metabolism. Mol Metab 2014 Mar 19;3(4):372-383 [FREE Full text] [doi: 10.1016/j.molmet.2014.03.002] [Medline: 24944897]

24. Hadlow NC, Brown S, Wardrop R, Henley D. The effects of season, daylight saving and time of sunrise on serum cortisol in a large population. Chronobiol Int 2014 Mar;31(2):243-251. [doi: 10.3109/07420528.2013.844162] [Medline: 24156521]

25. Mason I, Qian J, Adler G, Scheer FA. Impact of circadian disruption on glucose metabolism: implications for type 2 diabetes. Diabetologia 2020 Mar;63(3):462-472 [FREE Full text] [doi: 10.1007/s00125-019-05059-6] [Medline: $\underline{31915891]}$

26. Kalsbeek A, Yi CX, La Fleur SE, Fliers E. The hypothalamic clock and its control of glucose homeostasis. Trends Endocrinol Metab 2010 Jul;21(7):402-410. [doi: 10.1016/j.tem.2010.02.005] [Medline: 20303779]

27. Bright GM, Melton TW, Rogol AD, Clarke WL. Failure of cortisol blockade to inhibit early morning increases in basal insulin requirements in fasting insulin-dependent diabetics. Diabetes 1980 Aug;29(8):662-664. [doi: 10.2337/diab.29.8.662] [Medline: 7002678] 
28. Huang W, Ramsey KM, Marcheva B, Bass J. Circadian rhythms, sleep, and metabolism. J Clin Invest 2011 Jun;121(6):2133-2141 [FREE Full text] [doi: 10.1172/JCI46043] [Medline: 21633182]

29. Cailotto C, La Fleur SE, Van Heijningen C, Wortel J, Kalsbeek A, Feenstra M, et al. The suprachiasmatic nucleus controls the daily variation of plasma glucose via the autonomic output to the liver: are the clock genes involved? Eur J Neurosci 2005 Nov;22(10):2531-2540. [doi: 10.1111/j.1460-9568.2005.04439.x] [Medline: 16307595]

30. Christesen H, Brusgaard K, Hussain K. Recurrent spontaneous hypoglycaemia causes loss of neurogenic and neuroglycopaenic signs in infants with congenital hyperinsulinism. Clin Endocrinol (Oxf) 2012 Apr;76(4):548-554. [doi: 10.1111/j.1365-2265.2011.04250.x] [Medline: 21981106]

31. Jauch-Chara K, Hallschmid M, Gais S, Oltmanns KM, Peters A, Born J, et al. Awakening and counterregulatory response to hypoglycemia during early and late sleep. Diabetes 2007 Jul;56(7):1938-1942 [FREE Full text] [doi: 10.2337/db07-0044] [Medline: 17400929$]$

32. Whincup G, Milner RD. Prediction and management of nocturnal hypoglycaemia in diabetes. Arch Dis Child 1987 Apr;62(4):333-337 [FREE Full text] [doi: 10.1136/adc.62.4.333] [Medline: 3296962]

33. van Beers CA, DeVries JH. Continuous glucose monitoring: impact on hypoglycemia. J Diabetes Sci Technol 2016 Nov 01;10(6):1251-1258 [FREE Full text] [doi: 10.1177/1932296816653411] [Medline: 27257169]

34. Graveling AJ, Frier BM. The risks of nocturnal hypoglycaemia in insulin-treated diabetes. Diabetes Res Clin Pract 2017 Nov;133:30-39. [doi: 10.1016/j.diabres.2017.08.012] [Medline: 28888993]

35. Mukherjee E, Carroll R, Matfin G. Endocrine and metabolic emergencies: hypoglycaemia. Ther Adv Endocrinol Metab 2011 Apr;2(2):81-93 [FREE Full text] [doi: 10.1177/2042018811401644] [Medline: 23148173]

36. Hall H, Perelman D, Breschi A, Limcaoco P, Kellogg R, McLaughlin T, et al. Glucotypes reveal new patterns of glucose dysregulation. PLoS Biol 2018 Jul 24;16(7):e2005143 [FREE Full text] [doi: 10.1371/journal.pbio.2005143] [Medline: 30040822]

37. Colas A, Vigil L, de Castro CR, Vargas B, Varela M. New insights from continuous glucose monitoring into the route to diabetes. Diabetes Metab Res Rev 2018 Jul;34(5):e3002. [doi: 10.1002/dmrr.3002] [Medline: 29516622]

38. Lunt H, Heenan HF. Diagnosing the underlying cause of mild hyperglycemia using interstitial glucose data. J Diabetes Sci Technol 2020 Nov;14(6):1139-1140 [FREE Full text] [doi: 10.1177/1932296820929369] [Medline: $\underline{\text { 32462915] }}$

39. Larkin ME, Nathan DM, Bebu I, Krause-Steinrauf H, Herman WH, Higgins JM, GRADE Research Group. Rationale and design for a GRADE substudy of continuous glucose monitoring. Diabetes Technol Ther 2019 Dec;21(12):682-690 [FREE Full text] [doi: 10.1089/dia.2019.0202] [Medline: $\underline{\text { 31393176] }}$

40. Radhakrishnan K, Kim MT, Burgermaster M, Brown RA, Xie B, Bray MS, et al. The potential of digital phenotyping to advance the contributions of mobile health to self-management science. Nurs Outlook 2020;68(5):548-559. [doi: 10.1016/j.outlook.2020.03.007] [Medline: 32402392]

41. Ziegler R, Heinemann L, Freckmann G, Schnell O, Hinzmann R, Kulzer B. Intermittent use of continuous glucose monitoring: expanding the clinical value of CGM. J Diabetes Sci Technol 2021 May;15(3):684-694 [FREE Full text] [doi: 10.1177/1932296820905577] [Medline: 32064909]

42. Yang Q, Hatch D, Crowley M, Lewinski AA, Vaughn J, Steinberg D, et al. Digital phenotyping self-monitoring behaviors for individuals with type 2 diabetes mellitus: observational study using latent class growth analysis. JMIR Mhealth Uhealth 2020 Jun 11;8(6):e17730 [FREE Full text] [doi: 10.2196/17730] [Medline: 32525492]

43. Chrisworth88 - Basic-CGM-analysis-for-CHI. GitHub. URL: https://github.com/chrisworth88/Basic-CGM-analysis-for-CHI [accessed 2021-09-28]

44. Banerjee I, Salomon-Estebanez M, Shah P, Nicholson J, Cosgrove KE, Dunne MJ. Therapies and outcomes of congenital hyperinsulinism-induced hypoglycaemia. Diabet Med 2019 Jan;36(1):9-21 [FREE Full text] [doi: 10.1111/dme.13823] [Medline: 30246418]

45. Ghosh A, Banerjee I, Morris AA. Recognition, assessment and management of hypoglycaemia in childhood. Arch Dis Child 2016 Jun;101(6):575-580. [doi: 10.1136/archdischild-2015-308337] [Medline: 26718813]

46. Demirbilek H, Hussain K. Congenital hyperinsulinism: diagnosis and treatment update. J Clin Res Pediatr Endocrinol 2017 Dec 30;9(Suppl 2):69-87 [FREE Full text] [doi: 10.4274/jcrpe.2017.S007] [Medline: 29280746]

47. Liang Y, Zheng X, Zeng DD. A survey on big data-driven digital phenotyping of mental health. Inf Fusion 2019;52:290-307. [doi: 10.1016/j.inffus.2019.04.001]

48. Pickup JC, Ford HM, Samsi K. Real-time continuous glucose monitoring in type 1 diabetes: a qualitative framework analysis of patient narratives. Diabetes Care 2015 Apr;38(4):544-550. [doi: 10.2337/dc14-1855] [Medline: 25552422]

49. Buckingham B, Block J, Burdick J, Kalajian A, Kollman C, Choy M, Diabetes Research in Children Network. Response to nocturnal alarms using a real-time glucose sensor. Diabetes Technol Ther 2005 Jun;7(3):440-447 [FREE Full text] [doi: 10.1089/dia.2005.7.440] [Medline: 15929675$]$

\section{Abbreviations \\ CGM: continuous glucose monitoring \\ HI: hyperinsulinism}


IKH: idiopathic ketotic hypoglycemia

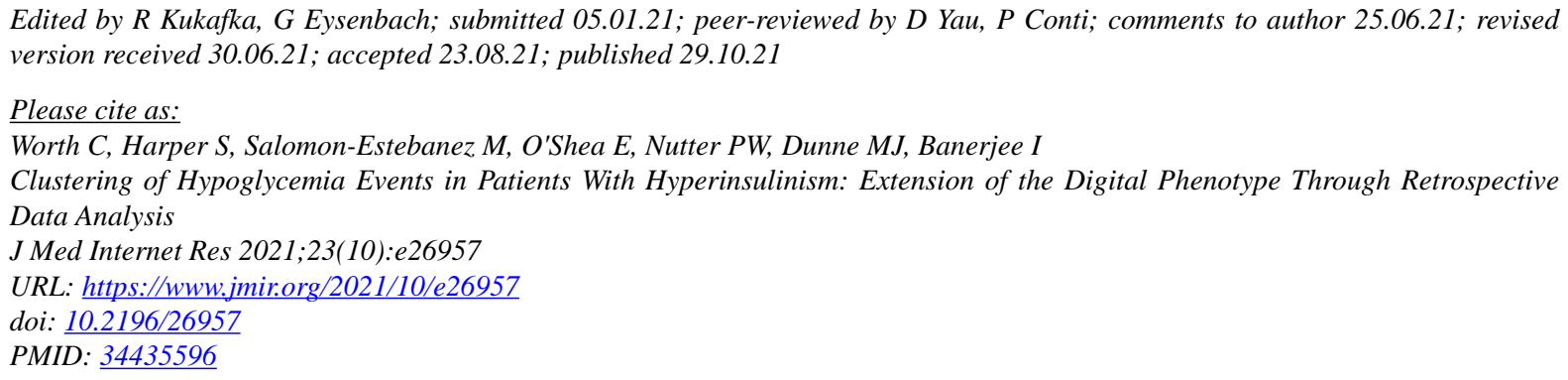

CChris Worth, Simon Harper, Maria Salomon-Estebanez, Elaine O'Shea, Paul W Nutter, Mark J Dunne, Indraneel Banerjee. Originally published in the Journal of Medical Internet Research (https://www.jmir.org), 29.10.2021. This is an open-access article distributed under the terms of the Creative Commons Attribution License (https://creativecommons.org/licenses/by/4.0/), which permits unrestricted use, distribution, and reproduction in any medium, provided the original work, first published in the Journal of Medical Internet Research, is properly cited. The complete bibliographic information, a link to the original publication on https://www.jmir.org/, as well as this copyright and license information must be included. 